\title{
Private sponsorships and independent film exhibition in Taiwan
}

Authors: Hongchi Shiau and Karina Aveyard

\begin{abstract}
Following the deregulation of the Taiwanese film exhibition industry in the late 1990s, local movie theatres have increasingly spurned domestic productions in favour of more dependable Hollywood blockbusters. With little commercial support for the screening of their projects, independent filmmakers in Taiwan have begun to turn to private sponsors as a means of securing theatrical deals. This article explores the historical development of this practice and examines how it has helped some filmmakers overcome the structural and economic constraints that affect domestic productions at the cinema. The article is based on research conducted by Hongchi Shiau over a five-year period in Taiwan.
\end{abstract}

At the dawn of new millennium, the highly-respected British film magazine Sight and Sound published its list of the ten greatest films of the twenty five years. Among more obvious selections, such as Raging Bull (Scorsese 1980) and Fanny and Alexander (Bergman 1982), was Yi $Y i$ (alternate English title: A One and a Two...), an unassuming family drama from Taiwan (Sight and Sound 2002). Director, Edward Yang, was lauded internationally for the film with recognition including the award for Best Director award at the Cannes Film Festival in 2000 (Festival De Cannes 2000), but $Y i Y i$ failed to secure theatrical release in its home country. As a Taiwanese cinephile, who is also an expatriate in the United States, Hongchi Shiau was able to see $Y i-Y i$ in Philadelphia as part of its international release. However, it was only after Yang died in 2007 the film was finally screened in Taiwan during a special session of the Golden Horse Film Festival titled 'Paying Tribute to Edward Yang'.

While the circulation of art and other specialised cinemas often depends on distribution networks that are positioned outside the commercial mainstream (Lobato 2007:116), the situation of an internationally acclaimed movie like $Y i$-Yi failing to achieve a release in its home country is almost unprecedented. It is, however, symptomatic of a broader trend in Taiwanese film exhibition away from screening local product at cinemas, but this has not always been the case. Domestic films flourished in Taiwan in the 1970s and into the early 1980s (see Hong 2011, Yeh 2006: 156168), but over the past twenty years or so their public exhibition has been in decline. This downward trend is attributable to a number of factors including shifts in the creative and stylistic direction of local filmmaking, ticket pricing strategies, as well as the impact of more general political and economic reforms. When quota restrictions on the import of foreign films were lifted 
in 1997 as part of a larger program of media deregulation, the market was opened to an uncapped supply blockbuster releases from Hollywood. Films from the U.S. proved popular with Taiwanese audiences and within the space of only a few years were accounting for the vast majority of box office revenues. Foreign movies have long been part of the Taiwanese film landscape, but before media deregulation international titles came predominantly from China and South-East Asia. Their presence on Taiwanese cinema screens was generally accepted without the cultural angst that accompanied the influx of Hollywood cinema from the late 1990s onwards (Berry 2009: 140-153, Curtin 2007: 85-108)

The gradual economic and cultural devaluation of local cinema that has taken place within Taiwan over the past two decades has been a cause for concern for the national government and filmmakers alike. For its part, the government has attempted to reinvigorate the domestic industry through a series of grants and incentives. These programs have been directed principally at supporting the cost of film production, and more recently have been expanded to include incometax breaks for production companies to help them develop an ongoing slate of projects (Taiwan GIO 2011a). The government also supports some smaller grants for film marketing and cinema exhibition. Outside this subsidy system, opportunities exist for a handful of highly successful directors to attract funding from Hollywood studios for their productions - examples include Ang Lee's Crouching Tiger, Hidden Dragon (2000) and Kuo-fu Chen's Double Vision (2002), both funded by Sony Pictures-Columbia (IMDB 2011, Davis and Yeh 2008: 61). At the other end of the spectrum, a limited amount of private finance circulates for low budget, independent productions. A sizeable proportion of this money emanates from rich families for the purpose of supporting the filmmaking projects of their offspring. For filmmakers working on independent projects, securing a theatrical release is seen as vitally important to enhancing their professional reputation and establishing a track record that will help them attract government funding in the future. In more immediate terms, a successful cinema release is also valued for its capacity to boost sales in subsequent windows such as DVD sales, television and Internet downloads (Acland, 2003: 157159). However, with movie theatres reluctant to divert precious screen time away from dependable Hollywood product in favour of more risky locally-made films, securing a cinema release for an independent project is typically difficult to achieve.

In the period since media deregulation, Taiwanese film scholarship has tended to be preoccupied with the impact of the globalising forces of Hollywood. While the negative impacts of cultural colonisation formed the focus of early research, this has given way to studies engaged with the more nuanced complexities of the Taiwanese-US cinematic relationship. Research centred on 
the latter has explored the way in which domestic cinema production has been reconfigured by the assimilation of the external factors (i.e. Hollywood money and creative techniques), but, at the same time, how international circulation of the Taiwanese films produced under these conditions has in turn reshaped Hollywood and the broader global film landscape (see Davis and Chen 2007, Wang and Yeh 2005). Scholars have also become increasingly interested domestic film production activity in its local and regional contexts, and the efforts of filmmakers to re-engage Taiwanese audiences (see Davis and Yeh 2008: 60-63, Hong 2011, Yeh and Davis 2005). However, within these discourses little consideration has been given to the way in which the accessibility and reception of domestic films is shaped by the economic and culturally regulated processes of distribution and exhibition. While researchers such as Karina Aveyard (2011), Hjort and Mackenzie (2000) and Ramon Lobato (2007) have begun to examine these questions in other national contexts, the means by which independent films in particular circulate within Taiwan remains poorly understood. This is the gap this article seeks to address.

Specifically this article examines the rise of sponsor-supported theatrical releases for lowbudget, independent films in Taiwan. Under these arrangements benefactors guarantee the viability of a film's cinematic run by pre-purchasing large numbers of tickets for its screenings. While the scale of the releases supported by sponsors is typically fairly small (generally less than 10 screens), this practice has nonetheless helped an increasing number of Taiwanese films reach domestic movie theatre audiences and aided their overall commercial and critical success. The discussion is based on empirical research conducted over a five year period by Hongchi Shiau. During this time he attended thirteen screenings held in four different movie theatres across Taipei - as the hub of domestic cinema-going activity, the city has been at the centre of sponsored screenings phenomenon. Despite containing only 15 percent of the nation's population, Taipei generally accounts for around 50 per cent of box office revenues (Taiwan GIO 2005). In addition to attending screenings, Shiau interviewed six film distributors and eleven directors who had been involved with sponsored releases. Shiau also attended meetings between distributors and cinema theatre owners to observe negotiations over the staging of sponsored events. 


\section{Film exhibition in Taiwan - a brief recent history}

During the 1970s and into the early 1980s film production in Taiwan thrived on a fairly steady output of martial arts and romantic films that were popular both domestically and throughout South Asia (Chung 2006). After the lifting of martial law in 1987, Taiwanese cinema began to diversify as filmmakers became free to explore a range of political and social themes that had been previously off limits. The 'New Wave Cinema' movement, as it became known, established Taiwan as a centre for quality art film production, for which it is possibly best known today (Davis and Yeh 2008: 60). However, while the New Wave films resonated with international audiences and critics, they were far less enthusiastically received at home. Instead many cinema-goers turned to more straightforward B-grade films emanating from Hong Kong and elsewhere in Asia, which were also accessible at a lower ticket price. Admission to Taiwanese films, in contrast, usually came at a premium that brought them into direct competition with Hollywood releases and other forms of entertainment such as karaoke parlours and video game kiosks. Traditional Chinese distributors were also deemed to be slow to catch up with new marketing techniques that were widely adopted by Hollywood distributors following the abolition of martial law (Curtin 2007: 106-108).

Into the 1990s the situation for local films worsened as Taiwan embarked on an extensive program of media deregulation. Most significantly for the film industry these initiatives led to a relaxation of the previously strict quota restrictions on imported films, and the ownership of cinema theatres being opened to foreign nationals. These reforms paved the way for the Hollywood studios to dramatically increase their share of the Taiwanese box office by multiplying the number of films in the market and gaining control of the cinemas in which they would be exhibited. Box office revenues for domestically-made films, which were already in decline, began to slide even further. Within ten years of deregulation the number of local movies released at cinemas had fallen by 50 per cent and the domestic industry's share of earnings had fallen as low as 0.1 per cent (in 2001) (Chiang n.d., Taiwan GIO 2005). These trends pushed Taiwanese films even further to the periphery of public exhibition as they became increasingly shunned by movie theatres in favour of more reliable Hollywood fare.

Concerned primarily about the cultural impact of the decline in domestic film production, the Taiwanese government responded by introducing a range of measures designed to help the local industry to regain its competitiveness. Dating back to the early 1990s the government has been offering production subsidies for local films and in 2004 income-tax breaks were introduced for selected production companies (Chung 2007, Chiang n.d.). Access to this funding is determined 
primarily on a filmmaker's track record of financial success. One of the most successful government-funded film to have emerged in recent years is the romantic comedy Cape No. 7 (TeSheng Wei 2008). It was one of the highest grossing films (domestic and international) in Taiwan in 2008, earning NT\$530 million (at the time worth around US\$16 million) from a theatrical run that lasted four months (Hsu 2009). The film had a reported budget of NT $\$ 50$ million, of which the government contributed NT\$5 million (China Post 2008). Cape No.7 is seen by some industry commentators as pivotal in encouraging Taiwanese audiences to consider more favourably on the option of paying to see a locally-made film (Hsu 2009, Lin 2008, Davis 2007: 155-156).

In belated recognition of the important role that is played by distribution and exhibition in determining the success of local productions, the Taiwanese government recently introduced two new subsidies targeted specifically at these sectors. From 2008 the annual top local box office performers have been awarded bonus payments, which are intended to be put towards the development and production of future projects (Taiwan GIO 2011b). These also provide an additional incentive for filmmakers to maximize returns from a movie's theatrical release. To enhance screening opportunities for local films, a second scheme introduced in the same year, offers subsidies to movie theatres that agree to screen them. The subsidy operates on a sliding scale that increases based on the number of screenings a film has at a particular cinema. It also takes into account the size and location of the cinema, so as to offer greater rewards to more marginal cinema operations. While these screening subsidies have been welcomed they are not, in most cases, of sufficient value to dramatically alter the commercial case for a film's cinema release.

\section{Sponsored screenings}

It is within this cinematic landscape that sponsored screenings have emerged as an alternative means of securing a theatrical release for low-budget, independent films. Under this model, benefactors buy large numbers of advance tickets, which assures the cinema screening the film of a substantive minimum return on its theatrical run. Efforts are generally concentrated in the first week of a film's release when sponsored ticket holders are strategically deployed to fill vacant seats at screenings. The aim is to create the perception of popularity and, from this, generate positive word-of-mouth publicity. These events typically take place at in fairly intimate auditoriums with seating capacities of around 40-60, which are found in both small independent and multiplex cinemas in Taipei. For some very small or specialised films distributors will sometimes opt for a 'half-screen release', whereby the movie will alternate with another title in the same auditorium for a short period. With fewer screenings per day to fill, the distributor is able to prolong a film's 
theatrical exposure and provides more time to build audience awareness.

Film sponsors can be classified into two main types - those whose support is driven by their personal or professional relationship to the filmmaker/s, and those who are attracted primarily by the film's subject matter. Non-content related sponsors are typically derived from the kinship networks (family and friends) of the director and other film crew. These benefactors are motivated primarily by their personal connection, which means they will often agree to support a film even if not particularly interested in its subject matter.

Content related sponsors, on the other hand, are drawn from a diverse range of sources. They include organizations interested in promoting certain political or social views, raising money for charity work or simply selling their goods or services. For example the documentary The Long Goodbye (Yang Li-Zhou 2010), which depicts the struggles of seven Alzheimers patients in Taiwan, attracted sponsorship from several charities including the Catholic Foundation for Alzheimer \& Dementia Elderly (literal translation, Shyun 2010). In other instances particular social groups, such as the gay community, have been mobilised to support films designed to appeal to a particular audience. Gay-themed films including Formula 17 (Yin-jung Chen 2004), Eternal Summer (Leste Chen 2006), Spider Lilies (Zero Chou, 2007) and Miao-Miao (Hsiao-tse Cheng, 2008) are all examples of titles that have succeeded partly due to the support of private benefactors.

Tied more closely to commercial interests was the release of the film Island Etude (Huai-en Chen 2006). It charts an adventure of self-discovery by a cyclist and attracted a major block ticket purchase from Giant, a Taiwan-based international bicycle manufacturer. It also received sponsorships from over ten tourism-related groups who promote cycle-related tourism in Taiwan (interview with Huai-en Chen 17 may 2008). While these arrangements resemble the product placements that have become relatively common across film and television production in the United States, significant cultural and economic differences exist in this kind of support in Taiwan. Corporate sponsors typically keep a low profile or even remain anonymous because their overt association with a film is considered unwelcome and likely to alienate potential audiences. The commercial success of Island Etude (2007) encouraged a number of other tourism organisations to participate in sponsored screenings. These groups regularly invest in the production of films that intend to portray certain towns or regions in a favourable light, thereby helping to boost interest in a particular holiday destination. Increasingly these organisations have recognized the value of providing additional support for sponsored screenings as a means of ensuring that the films they invest in reach the widest audience possible. As Kaohsiung city mayor Chen reasoned: "if we have 
spent millions to produce a movie, how can we sit and see it dying in the theater" (Chen speech at Kaohsiung Film Festival 22 October 2010).

\section{Case studies - Let It Be and Comedy Makes You Cry}

Turning in more detail to Hongchi Shiau's research, this final section of the article examines two situations in which sponsored screenings have been utilised to support the theatrical release first the documentary Let It Be (Yen Lan-chuan and Juang Yi-tseng, 2004), and second the comedy/drama feature Comedy Makes You Cry (Zong-de Wu, 2010). These case studies provide examples of projects underpinned by content related and non-content based sponsors respectively. Shiau attended sponsored screenings of both titles, which, in different ways, demonstrate how private benefactors have enhanced the success of their film's release and reception.

Let It Be tells the story of an aging rice farmer and his wife whose livelihood is under threat as a result of the lifting of the ban on rice imports in Taiwan - a decision that was taken in anticipation of the nation's accession to the World Trade Organization in 2002. The agricultural policy on rice - a potent symbol of Taiwanese industry and more broadly its way of life - was highly controversial. This documentary explores the predicament of the protagonists who find that under the new liberalised trade conditions cultivating rice has become unprofitable but that the option of shifting to alternative crops is not economically viable either. Funded by Taiwan's Public Television Station, Let It Be was originally intended for television. However, its producers were encouraged to pursue a theatrical release after positive responses from its pre-release screenings.

The film was successful in attracting a range of private sponsors who sympathised with the farming family's plight and saw it as a platform to promote their political and social concerns. Benefactors included a number of anti-globalisation alliances, several social justice activists and even some politicians. ${ }^{\mathrm{i}}$ Let It $\mathrm{Be}$ was screened on five occasions in a small auditorium (40 seats) located with a multiplex in Taipei - each time to a full capacity audience that was assembled through the mobilisation of sponsored ticket holders to fill vacant seats. Small bamboo tubes of rice and pamphlets critical of the government's rice policy were given as souvenirs to everyone who attended the screenings. These gratuities were paid for by the film's sponsors as way of reinforcing the issues explored in the film. Let It Be has since screened to acclaim in a number of international film festivals including Durban in 2007 (Taipei Liaison Office in the Republic of South Africa 2007), although it has not brought about a change to the regulations governing rice imports. 
Comedy Makes You Cry exemplifies a different type of sponsorship, one in which the filmmaker rather than the film itself was the magnet for attracting private support. The plot centres on a man and a woman, both experiencing financial difficulties, who try to get work in the sex industry but fail to attract any clients. Ultimately the couple is delivered from their dire situation by the good fortune of a lottery win. The film is one of a number of light comedy/dramas that have emerged from Taiwanese filmmakers following the huge success of Cape No. 7 in 2008. Comedy Makes You Cry's director, Zong-De Wu, is a veteran television producer with over 30 years experience, with credits including former hit series Sky Eyes (1976-1978) and The Law Net (19781980). Drawing on his years of experience with television Wu explicitly set about making a film that would be 'funny, easy and light-hearted' and accessible to wide range of Taiwanese audiences. He was so committed to the project that he funded it from his own savings (interview with Zong-De Wu, 12 June 2010).

Comedy Makes You Cry was released in May 2010 and screened at Taiwanese cinemas for three weeks. Its box office receipts reached NT $\$ 12$ million, a respectable result for a relatively low budget film. With his extensive contacts within the television industry $\mathrm{Wu}$ was able to solicit support from a large number of private sponsors. He also targeted professional groups such as divisions of the International Rotary club in Taipei where he delivered speeches to promote the film and raise additional sponsorships. In these presentations $\mathrm{Wu}$ often jokingly likened the fortune of the Taiwanese filmmaker to that of a 'broke prostitute', lamenting the lack of money and support for the local industry. Shiau attended three separate sponsored screenings of Comedy Makes You Cry. The first was supported by a Rotary club, while the other two events were facilitated by some of Wu's former television industry colleagues. The screenings took place in a small 50-seat theatre, which like the screenings for Let It Be, were full on each occasion.

\section{Conclusion}

The longstanding resistance of movie theatres to showing locally-made films, and a national audience that seems more interested in stories emanating from Hollywood and elsewhere rather than their own country, are two issues that have beset the Taiwanese industry for several decades.

Within this environment, there has been limited capacity to support the work of aspiring filmmakers working on low budget, independent projects. Sponsored screenings have, on the one hand, emerged as a product of the economic constraints attributable to increased globalisation of film consumption in Taiwan. However, at the same time, these screenings also represent a phenomenon that moves outside these conditions by creatively mobilising local resources. While typically occurring on a small scale, sponsored screenings nonetheless demonstrate how targeted marketing 
strategies can be effectively used to facilitate theatrical release that in turn can enhance a movie's recognition and income.

This article contributes to an evolving area of research that is engaged with how the processes of distribution and exhibition shape the ways in which films reach, and do not reach, their intended audiences. The situation in Taiwan has a number of parallels with Australian cinema, where gaining access to local cinema screens is often similarly difficult to negotiate and where reasons for the lack of local audience appeal for domestic films has been hotly debated. Both provide examples of how globalised and localised film industries coexist in what is typically a highly uneven economic and cultural relationship. The rise of sponsored screenings in Taiwan provides an important counternarrative to the discourses that focus largely on the primacy of Hollywood. These screenings remind us that diverse and innovative cinematic activity can exist beyond the blockbuster and outside the imperatives of the multiplex exhibition environment.

\section{References}

Acland, Charles 2003, Screen Traffic: Movies, Multiplexes, and Global Culture, Durham: Duke University Press.

Aveyard, Karina 2011, 'Australian films at the cinema: rethinking the role of distribution and exhibition', Media International Australia, no. 138, pp. 36-45.

Berry, Chris 2009, 'Re-writing cinema: markets, languages, cultures in Taiwan', in Shih, Fang-long, Thompson, Stuart and Tremlett, Paul-Francois (eds) Re-writing Culture in Taiwan, London and New York: Routledge.

Chiang, Ying-Ming n.d., 'Taiwan and Hong Kong's Film Industries in the Context of Globalization', Globalization and Media, http://homepage.newschool.edu/ chakravs/YMCessay.html. Accessed 4 February 2011.

China Post 2008, “"Cape No.7” Gives Taiwan Film Industry Boost', 13 September, http://www.chinapost.com.tw/taiwan/arts\%20\&\%20leisure/2008/09/13/174526/Cape-No..htm Chung, Oscar 2006, 'And Action!' Taiwan Review, 1 January, http://taiwanreview.nat.gov.tw/ct.asp?xItem=1164\&CtNode=1369. Accessed 4 February 2011.

Curtin, Michael 2007, Playing to the World's Biggest Audience, Berkeley: University of California Press.

Davis, Darrel William 2007, 'Trendy in Taiwan' in Davis, Darrel William and Chen, Robert Rushou 2007, Cinema Taiwan: Politics, Popularity and State of the Arts, Routledge, London.

Davis, Darrel William and Yeh, Emilie Yueh-yu 2008, East Asian Screen Industries, London: British Film Institute.

Davis, Darrel William and Chen, Robert Rushou 2007, Cinema Taiwan: Politics, Popularity and State of the Arts, Routledge, London.

Festival De Cannes 2000, 'Awards 2000' http://www.festivalcannes.fr/en/archives/2000/awardCompetition.html. Accessed 2 February 2011.

Hjort, Mette and Mackenzie, Scott 2000, Cinema \& Nation, London: Routledge. Hong, Guo-Juin 2011, Taiwan Cinema: A Contested Nation on Screen, New York: Palgrave 
Macmillan

Hsu, Tien-ying 2009, 'Taiwanese Films Enter a New Era', Taiwan Today, 28 August,

http://www.taiwantoday.tw/fp.asp?xltem=61404\&CtNode=436. Accessed 22 February 2011.

Internet Movie Database (IMDB) 2011, www.imdb.com. Accessed 2 April 2011.

Lin, Hermina 2008, ““Cape No.7” shakes up Taiwan's film industry', Taiwan Culture Portal, 4

August, http://culture.tw/index.php?option=com_content\&task=view\&id=812\&Itemid=235.

Accessed 31 March 2011.

Lobato, Ramon 2007, 'Subcinema: Theorizing Marginal Film Distribution', Limina, 13,

http://www.limina.arts.uwa.edu.au/_data/page/59120/Lobato.pdf. Accessed 22 April 2010.

Shyun, Y. (translation) 2010, 'Ella \& Her Dementia Grandmother Lend a Hand in Director Yang Li-

Zhou's Latest Documentary Movie', 21 November,

http://asianfanatics.net/forum/topic/737159-ella-her-dementia-grandmother-lend-a-hand-in-

director-yang-li-zhous-latest-documentary-movie-the-long-goodbye/. Accessed 27 March

2011.

Sight and Sound 2002, 'UK Critics' Top Ten Poll', http://www.bfi.org.uk/sightandsound/feature/63. Accessed 2 February 2011.

Taipei Liaison Office in the Republic of South Africa 2007, 'South African Premiere of "Let It Be"

Well Received', 26 June,

http://www.taiwanembassy.org/za/ct.asp?xItem=32572\&ctNode $=2122 \& m p=402 \&$ nowPage $=2$

\&pagesize $=30$. Accessed 31 March 2011.

Taiwan Government Information Office 2005, 'Taiwan Cinema \& TV Industry Development

Strategy’, www.taiwancinema.com/public/attachment/592111565271.ppt. Accessed 2 April 2011.

Taiwan Government Information Office 2011a, 'Motion Picture Industry'

http://www.taiwan.gov.tw/lp.asp?ctNode=2345\&CtUnit=811\&BaseDSD=7\&mp=1007.

Accessed 26 March 2011.

Taiwan Government Information Office 2011b, 'Exhibition Subsidy and Box Office Performance Award Policy', http://tc.gio.gov.tw/ct.asp?xItem=56663\&ctNode=287. Accessed $31 \mathrm{March}$ 2011.

Wang, Georgette \& Yeh, Emilie Yueh-yu 2005, 'Globalization and hybridization in cultural products: The cases of Mulan and Crouching Tiger, Hidden Dragon,' International Journal of Cultural Studies, vol. 8, no. 2, pp. 175-188.

Yeh, Emilie Yueh-yu 2006, 'Taiwan: Popular Cinema's Disappearing Act' in Ciecko, Anne Tereska (ed) Contemporary Asian Cinema, New York: Berg.

Yeh, Emille Yueh-yu and Davis, Darrel William 2005, Taiwan Film Directors: A Treasure Island, Columbia University Press, New York City.

Hong-Chi Shiau is an Associate Professor in the Communications Management Department at Shih-Hsin University, Taiwan. His research centres on the intersections between media consumption and identity formation.

Karina Aveyard is PhD candidate in the School of Humanities at Griffith University. Her doctoral research examines cinema exhibition and attendance in regional and rural Australia and is funded by an ARC Linkage grant with industry partners the National Film and Sound Archive and Screen 


\section{Australia.}

${ }^{\text {i }}$ Hongchi Shiau was invited to one of the film's screenings by an environmental activist who is also a member of Taiwan's Green Party. 